\title{
MALAM BARETONG SEBAGAI SUMBER PENCIPTAAN KOMPOSISI “NIGHT OF BAGHETONG"
}

\author{
Vereki Martiano, Asep Saepul Haris, Asril \\ Program Studi Penciptaan dan Pengkajian Seni \\ Penciptaan Musik Nusantara \\ Program Pascasarjana Institut Seni Indonesia Padangpanjang \\ E-mail : mvereki@gmail.com, Hp. 081365653559
}

\begin{abstract}
Baretong night is one of mutual help activities namely donation in wedding party done at the time of counting the money gotten from the guests that present in the last night or closing night of the wedding party in Pariaman Limau Purut. Based on the positive and negative views, this event gives the impact of solution in the aspect of assessing the culture particularly in the social value. Therefore, the message of musical composition embodied from extramusical things was done by using the concept of musical analogy through conventional and non-conventional instruments dialogically and sound experiment with the composition of tradition reinterpretation.
\end{abstract}

Kata kunci : Baretong, Positive, Negative, Extramusical, Musical Analogy.

\section{ABSTRAK}

Malam baretong merupakan salah satu kegiatan gotong royong, sumbangmenyumbang dalam pesta perkawinan yang dilakukan pada saat menghitung uang dari para tamu yang hadir pada malam terakhir atau malam penutupan perelatan di Pariaman Limau Purut. Berdasarkan pandangan positif dan negatif yaitu pada nilai social yang terjadi, memberikan dampak solusi dalam segi menilai kebudayaan. Sehingga pesan dari komposisi musik yang diwujudkan dari hal-hal ekstramusikal digarap dengan menggunakan konsep bentuk analogi musikal melalui instrument konfensional dan non konfensional secara berdialog dan eksperimental bunyi dengan garapan re-interpretasi tradisi.

Kata kunci : Baretong, Positf, Negatif, Ekstramusikal, Analogi Musikal.

\section{PENDAHULUAN}

Malam baretong merupakan salah satu kegiatan gotong royong, sumbang-menyumbang dalam pesta perkawinan yang dilakukan pada saat menghitung uang dari para tamu yang hadir sesuai dengan kebiasaan masyarakatnya dimana kegiatan ini dilaksanakan pada malam terakhir atau malam penutupan perelatan (pesta perkawinan) yang ada di daerah Limau Purut Pariaman. Kegiatan malam baretong ini tentu mempunyai pendukung seperti marapulai, anak daro, keluarga sipangka, niniak mamak, kapalo mudo, ketua pemuda, wali nagari dan masyarakat kampung yang ikut serta dalam kegiatan pesta perkawinan, bentuk 
prosesi malam baretong ini ada dua pihak yaitu malam baretong pihak anak daro dan pihak marapulai ${ }^{1}$.

Dilihat dari sejarahnya, malam beretong ini di awali karena adanya istilah "uang hilang dan uang jemputan'” yang diberikan kepada calon pengantin perempuan kepada keluarga calon pengantin laki-laki, hal ini dikarenakan awal tahun 1950-an, ada satu keluarga kaya di wilayah pariaman kemudian mereka risau dikarenakan anak gadis mereka yang sudah dewasa sedang menapak jadi perawan tua, keluarga kaya di wilayah tersebut itu menempuh cara yang tidak biasa, dengan jalan menyiarkan dari mulut ke mulut bahwa ia akan mengeluarkan sejumlah uang sebagai bonus yang disebut dengan "uang hilang"2.

Kemudian masyarakat yang menyumbang juga mempunyai kontribusi seperti keadaan status derajat seperti kekayaan tinggi, sedang, dan rendah contohnya; bupati, wali nagari, niniak mamak, pegawai negeri status kekayaan tinggi dan sedang berkisaran Rp. 300.000.00 - Rp. 1000.000.00, sedangkan seperti tukang panjek kambia, tukang ojek dan lain lain atau yang berada pada status rendah berkisaran $\mathrm{Rp}$. 50.000.00 - Rp. 200.000.003.

Perkawinan adalah suatu pola sosial yang disetujui dan disepakati oleh dua orang atau lebih untuk membentuk keluarga yang bahagia. Perkawinan tidak hanya mencakup hak melahirkan

1 Wawancara Bapak Bujang di Nagari Limau Purut, Padang Pariaman. 2017

2 Wawancara Bapak Bujang di Nagari Limau Purut, Padang Pariaman. 2017

3 Wawancara Bapak Bujang di Nagari Limau Purut, Padang Pariaman. 2017 dan membesarkan anak, tetapi juga seperangkat kewajiban dan hak istimewa yang mempengaruhi banyak orang. Arti sesungguhnya dari perkawinan adalah penerimaan status baru, dengan sederetan hak dan kewajiban yang baru, serta pengakuan akan status baru oleh orang lain (Horton, 1984: $270)^{4}$. Bagi orang Minangkabau, perkawinan haruslah memenuhi ketentuan adat yang berlaku di tengah masyarakat. Salah satu prosesi dat tersebut adlaah adat perkawinan. Seperti mamangan yang berbunyi "cupak diisi, limbago dituang", yang artinya ada aturan tersendiri untuk memenuhi suatu kewajiban dalam adat Minangkabau yang berhubungan dengan adat dalam upacara perkawinan.

Masyarakat Minangkabau melakukan perkawinan jika telah dipenuhi persyaratan-persyaratan yaitu; 1) calon mempelai harus beragama Islam; 2) calon mempelai tidak sedarah atau tidak berasal dari suku yang sama; 3) adanya sikap saling menghormati dan menghargai orangtua dan keluarga kedua belah pihak; dan 4) calon mempelai pria harus mempunyai sumber penghasilan untuk dapat menjamin kehidupan keluarganya. Selain itu masih ada tata krama dan upacara adat dan ketentuan agama Islam yang harus dipenuhi seperti tata krama japuik manjapuik, pinang maminang, batuka tando, baralek, jalang manjalang, dan badantam, baretong dan sebagainya 5 .

\footnotetext{
${ }^{4}$ Horton, Paul B dan Chester L. Hunt. 1984. Sosiologi Jilid 1 Edisi Keenam. Jakarta: Penerbit Erlangga.

5 Wawancara Asril Muchtar, Padangpanjang dan Pariaman 2017
} 
Bentuk prosesi acara malam baretong anak daro dan marapulai ini memiliki tiga tahap yaitu tahap pertama masyarakat pendukung sekitar kampung dan kenagarian berkumpul di rumah marapulai atau anak daro. Mereka dijamu dengan makan bajamba yang di awali oleh janang untuk memanggil niniak mamak, urang sumando, wali nagari, kapalo mudo, keluarga sipangka dan pemuda kampung.

Pada tahap kedua adalah mahimbau (memanggil) yang dilakukan tukang janang. Janang menghimbau para pendukung seperti niniak mamak, urang sumando, wali nagari, kapalo mudo, pemuda dan perwakilan keluarga sipangka untuk duduk di tikar atau lapiak yang terbentang6. Mereka akan bersiap untuk menghitung jumlah uang yang ada dalam kotak resepsi anak daro. Berbeda dengan malam baretong di tempat marapulai. Kotak resepsi yang berisikan amplop uang dibawa ke dalam rumah marapulai. Uang tersebut tidak dihitung di tikar atau lapiak Hanya keluarga marapulai yang tahu isi kotak resepsi yang di hitung di lingkup keluarga marapulai itu sendiri. ${ }^{7}$

Pada tahap ketiga adalah baretong (menghitung) yang dilanjutkan oleh tukang janang menghimbau kepada warga atau masyarakat sekitar dengan kata-kata:

"aa baa nyo niniak mamak, urang sumando, wali nagari, ketua pemuda, keluarga sipangka dan masyrakat kito, kok bajamba lah

\footnotetext{
6 Wawancara Bapak Bujang di Nagari Limau Purut, Padang Pariaman. 2017

7 Wawancara Bapak Bujang di Nagari Limau Purut, Padang Pariaman. 2017.
}

sudah moh, baa dek kini kok lai ado yang kabaretong malam ko" (bagaimana ninik mamak, orang semenda, wali nagari, ketua pemuda, keluarga tuan rumah, dan masyarakat kita, jika makan sudah selesai, apakah kita akan malakukan penghitungan malam ini?)

Begitulah perkataan tukang janang tadi untuk menghimbau atau berpartisipasi dalam gotong royong tersebut ${ }^{8}$. Kemudian para tamu atau masyarakat sekitar merespon dan mengumpulkan uang kepada tukang janang. Setelah itu di respon lagi oleh tukang janang:

"aaa si man geneang dari kampuang tangah, duo ratuih ibu mungko balakang"

(Si Man Geneang dari Kampung Tengah, dua ratus ribu suami istri)

Dari perkataan tukang janang tadi mengucapkan nama seseorang dan yang dimaksud dengan mungko balakang artinya suami istri. Hal ini dilakukan sampai pada akhir acara. Diakhir acara, janang kembali menutup prosesi malam baretong 9 .

Menurut Bujang bahwasanya malam baretong itu adalah sebuah kebudayan atau tradisi masyarakat kampung limau puruik yang bersifat gotong royong dan memiliki sistem sosial. Sedangkan menurut sudut pandang sebagian orang di luar

\footnotetext{
8 Wawancara Bapak Bujang di Nagari Limau Purut, Padang Pariaman. 2017.

9 Wawancara Bapak Bujang di Nagari Limau Purut, Padang Pariaman. 2017.
} 
Pariaman mengatakan bahwasanya malam baretong ini merupakan sifat ria, euoforia, atau badunia. Fenomena karya yang diciptakan berisi tentang nilai yang terkandung pada kegiatan malam baretong yaitu seperti kebersamaan, gotong royong, status sosial dan euoforia serta sisi positif dan negatif antara menunjukan sifat manusia.

\section{STUDI LITERATUR}

Erie Setiawan (2016:57) dengan judul buku Musik Untuk Kehidupan menyatakan bahwa dasar analogi pemahaman analisis musik adalah setiap musik yang kita dengarkan bisa terbangun atas dasar dorongan sempurna dari batin dan pikiran yang mengandung cita rasa, atau bisa pula dibuat secara "ngawur", bahkan spontan tanpa perencanaan sebelumnya. Peran analisa adalah membongkar "hasil" sekaligus "maksud" si pengarang musik tersebut. Musikologi membantu semua ini. Ilmuilmu lain membantu "menganalogikanya" seperti bunyi sebagai dasar musik bisa benar-benar berbunyi karena lahir atas kehendak manusia. Hal itu tidak bisa dipungkiri. Sesudah berkehendak manusia berimajinasi. Dan dariapadanya lahir yang kita sebut "fakta bunyi" yang mendasari pada teori dalam penciptaan musik.

Suka Hardjana (2003:78) dalam tulisannya yang berjudul Corat-coret musik kontemporer dulu dan kini mengatakan bahwa kata komposisi berasal dari bahasa asing yang berarti menyusun, mengatur atau merangkai dan dipergunakan secara khusus terutama untuk menandai sebuah karya musik Berdasarkan pendapat yang dikemukakan Suka Hardjana tersebut, pengkarya merealisasikannya melalui pencarian materi dan menyusun menjadi sebuah komposisi karawitan yang utuh yang bisa menyampaikan gagasan isi yang dilahirkan melalui bahasa musikal.

Shin Nakagawa (2000:64) dalam tulisannya yang berjudul Musik dan Kosmos; Sebuah Pengantar Etnomusikologi dijelaskan bahwa dalam musik sering terjadi peminjaman ciri khusus dari suatu budaya musik. Hal ini bisa melalui pertukaran instrumen musik di mana instrumen tersebut tidak harus disertai dengan konsep lamanya. Melalui pendapat Shin Nakagawa ini, pengkarya akan menggunakan beberapa media dari beberapa tradisi yang berbeda tanpa harus pengkarya mainkan dengan konsep asli dari media tersebut. Mediamedia yang akan pengkarya gunakan lebih pengkarya fungsikan sebagai alat penghasil bunyi dan penyampaian isi dari garapan komposisi musik ini, dalam artian media-media tersebut adalah media untuk mengembangkan ide gagasan baik secara konsep isi maupun bentuk. Di beberapa bagian media ini tetap bermain dengan konsep aslinya. Mengenai bentuk dan struktur, Suka Hardjana mengatakan bahwa dalam bentuk dan struktur inilah semua ketentuan dan keputusan rekayasa karya seni yang bersifat material (bunyi, suara, nada, ritme, harmoni dan seterusnya) dan non material (dinamik, sifat, watak, warna, rasa dan sebagainya) diakomodasikan (Nakagawa, 2000: 42).

Suka Hardjana menambahkan, di samping pengkarya melakukan penyu- 
sunan materi musikal, pengkarya juga mempertimbangkan pengolahan aspek non material seperti sifat, dinamik, watak, warna, rasa dan sebagainya demi terwujudnya sua- sana yang diinginkan dan tercapainya pesan yang ingin disampaikan.

Karya Hario Efenur (2016) dengan judul "Lamak Kato Lego Bunyi" yang merupakan komposisi musik nusantara yang berangkat dari fenomena budaya yaitu pasambahan. Fenoemena ini tidak diterjemahkan secara sederhana saja melainkan juga diterjemahkan ke dalam bahasa musikal, namun dilihat melalui nilai-nilai yang terkandung dalam pasambahan itu sendiri. Pengkarya juga menggunakan beberapa instrument konvensional dan non-konvensional agar terwujudnya pesan yang disampaikan. Sedangkan dalam karya yang akan pengkarya ciptakan bersumber dari fenomena kebudayan malam baretong serta pengkarya juga menggunakan instrument konvensional dan non-konvensional akan tetapi secara penggarapan berbeda dengan karakteristik "Dialog musik eksperimental menuju harmonisasi"pada karya ini.

Karya Susandra Jaya (2011) yang berjudul "Piaman Dalam Ritme", juga merupakan karya komposisi musik yang bersumber dari fenomena bajapuik yaitu berasal dari daerah Pariaman, yang mana tradisi bajapuik merupakan semacam prosesi sebelum terjadinya perkawinan dikarenakan ada beberapa pihak laki-laki yang dijemput melalui materi atau finansial. Dalam karya Susandra Jaya, penggarapan yang dilakukan adalah mengaitkan beberapa materi musikal kesenian tradisi Pariaman yaitu Gandang tambua, indang dan dampeang yang digarap secara inovatif. Sedangkan pengkarya juga berangkat dari fenomena yang ada di daerah Pariaman yaitu malam baretong. Namun ide tersebut melewati adanya prosesi perkawinan dan perhelatan. Secara garis besar garapan pengkarya berbeda dengan gaya garapan yang terdahulu yaitu menjadikan idiom kesenian tradisi lebih ke transformasi dialog musik eksperimental menuju harmonisasi pada karya "Nigth of Baghetong".

Karya Rayhan Redha Febrian (2017) yang berjudul "Langkah Para Randa", yang juga merupakan kompoisisi musik nusantara yang berangkat dari fenomena sosial yaitu janda, bagaimana janda merupakan seorang perempuan yang tidak mempunyai pasangan hidup. Karya ini juga menggunakan pendekatan postmodern serta fenomena "ekstramusikal" (tidak berhubungan dengan unsur musik ). Instrumen yang digunakan adalah konvensional dan non-konvensional. Sedangkan karya Nigth of Baghetong juga bersumber dari kasus "Ekstramusikal" yang mana pendekatan karya ini merupakan sebuah "dialog musik eksperimental menuju harmonisasi dengan instrumen konvensional dan non-konvensional pada penggarapan bunyi.

\section{METODE}

Dalam penciptaan karya "Night of Baghetong" ini pengkarya menggunakan konsep ekstramusikal dan analogi musik. Konsep inilah yang akan menjadi 
sumber ide penggarapan yang berangkat dari fenomena malam baretong yang dipilih pengkarya dalam penganalogian nilai positif dan nilai negatif serta memberikan pesan sosial dalam menyikapi segala aspek pandang positif dan negatif yang terkandung dalam fenomena malam baretong pada bentuk bunyi dan dialog atau responsorial. Tidak tertutup kemungkinan pengkarya juga mengaitkan beberapa kesenian yang cocok untuk penganalogian musik seperti kesenian indang Pariaman yang mempunyai struktur responsorial bunyi yang berkaitan dengan aspek positif dan negatif sehingga apa yang nantinya disampaikan oleh pengkarya melalui pendekatan garap re-interpretasi sehingga penonton (audiens) berhak memaknai apa saja (multitafsir) serta pada bentuk konsep ekstramusikal (konsep yang berhubungan di luar musik konfensional) yang telah direalisasikan pengkarya.

\section{HASIL DAN PEMBAHASAN}

Karya komposisi yang bersumber dari fenomena kegiatan malam baretong ini memberikan tawaran solusi dalam permasalahan pandangan positif dan negatif dengan nilai-nilai yang terkandung pada fenomena malam baretong. Tawaran ini akan diwujudkan pada bentuk konsep ekstramusikal dengan menganalogikan nilai positif dan nilai negatif dari sudut pandang orang pariaman maupun di luar pariaman yang sesuai dengan konsep bunyi yang menggunakan instrumen konvensional dan non konvensional. Namun tidak tertutup kemungkinan pengkarya juga akan mengaitkan materi kesenian indang pariaman dengan pengembangan ekperimental dan berdialog.

Pada tawaran ini pengkarya mencoba mengkerucutkan pandangan positif bahwasanya mempunyai nilai sosial seperti kebersamaan, tolong menolong dan gotong royong yang terjadi pada prosesi malam baretong sehingga mempunyai interaksi yang dan menjalin sebuah hubungan silahturahmi dengan masyrakat sekitar penuh kesan dan pesan yang sangat positif ketika di pandang melalui kaca mata pengkarya. Dari pandangan positif ini pengkarya akan menganalogikan bunyi serta musik yang bernuansa atau menggambarkan kebersamaan, keharmonisan serta jalinan hubungan komunikasi dan interaksi yang akan terwakili seperti konsep garap unisono, interlocking dan harmoni.

Sedangkan menurut pandangan negatif terkandung nilai kesenjangan yaitu seperti badunia, riak dan konflik serta menunjukan sifat manusia yang terpengaruh oleh sifat angkuh dan sombong dalam interaksi pada prosesi malam baretong tersebut sehingga menimbulkan terjadinya hubungan interaksi yang kurang baik dalam hidup bermasyarakat. Dari segi pandangan negatif ini pengkarya mencoba menganalogikan musikal tersebut dengan konsep musik yang terwakili yaitu konsonan, polimeter dan hocketing.

Realisasi pesan pada karya ini memberikan suatu pemikiran agar menilai sebuah kebudayaan atau tradisi kegiatan malam baretong harus mempunyai sudut pandang yang bersifat relatif dan tidak menilai dari luarnya sehingga memunculkan kondisi bentuk positif dan negatif dari memaknai 
sebuah kebudayaan. Dalam analogi musik memakai konsep musik repetisi yang mana alur penggarapan berjalan linear dengan penggabungan pandangan positif dan negatif sehingga pada bentuk gambaran musiknya berupa call and respon bunyi yang hadir dengan pengembangan dialog musik eksperimental.

Dari keseluruhan konsep capaian dalam penggarapan, pengkarya juga mewujudkan bunyi dengan menggunakan pendekatan garap re-interpretasi tradisi, yaitu tidak lagi diikat oleh ketentuan (pakem) atau aturan-aturan yang terdapat dalam kesenian atau budaya tradisi. Waridi mengatakan bahwa dalam pendekatan re-interpretasi tradisi, vokabuler musikal yang sudah diolah dan diaktualisasikan dalam wajah yang berbeda dengan bentuk asalnya (Waridi, 2008:63). Instrumen tradisi dan klasik barat serta non-konvensional hanya sebagai simbol penganalogian terhadap konsep karya dengan media yang digunakan seperti yaitu rapai, pupuak lambok, biola, kecapi, mandolin, accordion, bass, gitar, kecapi sunda, ganto, katuak-katuak, serta vokal sesuai dengan kebutuhan garapan.

Apapun bentuk karya seni tidak akan lahir begitu saja, gagasan yang dimiliki oleh seniman akan terwujud dalam beberapa tahapan kerja. Aspek ini lazim disebut dengan proses penggarapan. Demikian juga dengan komposisi musik ini akan diwujudkan dalam beberapa tahapan kerja yaitu;

\subsection{Preparation (Tahap Persiapan)}

Langkah pertama yang ditempuh sebelum melakukan proses pembuatan penciptaan komposisi musik nusantara ini adalah dengan mengumpulkan datadata yang menyangkut bagaimana malam baretong yang ada di Pariaman khususnya Limau Puruik, melalui beberapa metode-metode seperti:

a. Pendekatan Emik yaitu melakukan wawancara dan diskusi dengan beberapa informan, pelaku: niniak mamak, wali nagari, ketua pemuda, bundo kanduan, masyrakat setempat dan keluarga sipangka, yang mana hal tersebut menyangkut tentang informasi penting serta pengalaman.

b. Pendekatan Etik yaitu diskusi, wawancara dengan beberapa orang tokoh seperti: Dosen, pengampuh, janang, rang salapan. untuk memperkuat sumber ide dalam pengarapan karya penciptaan musik nusantara nantinya.

\subsection{Elaborasi}

Memperkuat gagasan yang akan dibangun pada penciptaan musik nusantara, proses pengarapan diawali dengan mempersiapkan materi-materi musik yang berangkat dari beberapa idiom-idiom musik tradisi Pariaman sebagai sumber kekuatan penggarapan musik tersebut. imajinasi seni tentunya akan memberikan ruang kreatifitas dan pembentukan konsep karya. 


\subsection{Sintesis}

Tahap mewujudkan konsep karya dengan mengumpulkan instrumentasi yang menyangkut dengan ide yang telah dibangun dengan idiom-idiom seperti alat musik konvensional: acordion, cello, mandolin, kecapi sunda, bass, udu, tri angle, biola, banjo dan gitar. Sedangkan instrument non-konvensional: katuakkatuak, roller bell, rapnar, cenglon, koin dan ganto, serta penggarapan vocalvocal yang bertemakan Pariaman.

\subsection{Realiasasi}

Proses perwujudan rancangan karya tersebut adalah melalui proses eksplorasi yang berkaitan dengan gagasan pengkarya seperti vocal pada prosesi malam baretong, simbol pada pelemparan koin yang berbeda bunyi, patatah petitih prosesi malam baretong ditransformasikan, serta penambahan idiom pengembangan indang, gandang tambua dan dampeang yang diolah dengan instrumen-instrumen konvensional daan non-konvensional untuk perwujudan karya. Berdasarkan proses tersebut diharapkan konsep gagasan dan material tercapai dalam satu kesatuan musik yang dapat tersampaikan dengan pesan musikal tersebut ke dalam penciptaan komposisi musik nusantara.

\subsection{Penyelesaian Karya}

Setelah bagian dari komposisi musik nusantara ini mulai terbentuk barulah pengkarya memberikan variasivariasi inovatif yang sesuai dengan ide perbagian dalam penciptaan musik nusantara ini, agar penciptaan musik nusantara ini lebih terlihat tergarap.
Dalam tahap ini merupakan tahap finising dalam karya yang berjudul "Night Of Baghetong" pengkarya melakukan proses latihan, pada saat latihan tersebut dilakukan latihan perbagian satu persatu dan proses latihan dilakukan secara berulang-ulang agar karya tersebut sesuai dengan konsep atau ide pengkarya.

\section{PENUTUP}

Komposisi musik yang berangkat dari fenomena malam baretong ini memiliki dua nilai pandangan yaitu positif dan negatif yang lahir dari tanggapan masyarakat. Berdasarkan dari pesan yang ingin disampaikan bahwasanya dalam menilai kebudayaan orang lain kita harus menempatkan dan memandang nya secara netral atau tidak ada diskriminasi dalam menilai maupun yang dinilai. Dari sumber ide yang dikemukan lahir karya yang berjudul Night of Baghetong. Dalam konsep penggarapan karya akan memunculkan penafsiran tentang bagaimana permasalahan dari dua nilai yaitu pandangan positif dan pandangan negatif terhadap sebuah kebudayaan sehingga fenomena malam baretong di analogikan melalui bentuk bunyi dan musikal yang diterjemahkan dengan menggunakan instrumen konfensional dan non konfensional secara berdialog atau call and respons yang berpijak pada pendekatan garap re-interpretasi tradisi.

\section{DAFTAR PUSTAKA}

Efenur, Hario, M. (2016) "Lamak Kato Lego Bunyi". Laporan Karya Seni. Pascasarjana ISI Padangpanjang. 
Febrian, Redha, Rayhan. (2017). "Langkah Para Randa”. Laporan Karya Seni. Pascasarjana ISI Padangpanjang.

Hardjana, Suka. (2003). "Corat-coret Musik Kontemporer Dulu dan Kini" Jakarta: Ford Fondation dan Masyarakat Seni Pertunjukan Indonesia.

Horton, Paul B dan Chester L. Hunt. (1984). "Sosiologi Jilid 1 Edisi Keenam". Penerbit Erlangga. Jakarta.
Jaya, Susandra. (2011). "Piaman Dalam Ritme". Laporan Karya Seni. Pascasarjana ISI Surakarta.

Nakagawa, Shin. (2000). "Musik dan Kosmos": Sebuah Pengantar Etnomusikologi". Jakarta : Yayasan Obor Indonesia.

Setiawan, Erie. (2016). "Musik Untuk Kehidupan". Yogyakarta: art music today. 